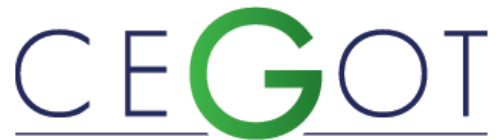

Centro de Estudos de Geografia e Ordenamento do Território
Geografia e Ordenamento do Território, Revista Eletrónica Centro de Estudos de Geografia e Ordenamento do Território http://cegot.org

ANDRADE, JANE

PPGeo/Faculdade de Ciências Humanas/Universidade do Estado de Mato Grosso

CEP 78200-000, Avenida Tancredo Neves, 1095, Cáceres, Brasil Janeandrade81@hotmail.com

CARMO, JUDITE

PPGeo/Faculdade de Ciências Humanas/Universidade do Estado de Mato Grosso

CEP 78200-000, Avenida Tancredo Neves, 1095, Cáceres, Brasil Judite.carmo@unemat.br

\title{
Entre o ideal e o real: o Plano Diretor e a realidade do córrego Sangradouro e a expansão urbana de Cáceres, Mato Grosso, no período de 1986 a 2016 \\ Between the ideal and the real: the master plan and the reality of the Sangradouro creek and urban expansion of Cáceres, Mato Grosso, from 1986 to 2016
}

Referência: Andrade, Jane; Carmo, Judite (2018). Entre o ideal e o real: o Plano Diretor e a realidade do córrego Sangradouro e a expansão urbana de Cáceres, Mato Grosso, no período de 1986 a 2016. Revista de Geografia e Ordenamento do Território (GOT), n. ${ }^{\circ} 15$ (dezembro). Centro de Estudos de Geografia e Ordenamento do Território, p. 31-53, dx.doi.org/10.17127/got/2018.15.002

\section{RESUMO}

As intervenções em Áreas de Preservação Permanente de córregos urbanos têm, ao longo dos anos, os colocado em risco, assim como a própria população. Nesse cenário, objetivouse analisar a degradação do córrego Sangradouro em Cáceres, Mato Grosso; e, verificar como a gestão municipal, por meio de seu Plano Diretor, tem contribuído para esse processo, por meio de uma abordagem qualitativa, com o uso de pesquisa bibliográfica, de campo e documental, de entrevista e questionário. Obteve-se como resultado que o canal está em parte descaracterizado e a sua degradação é visível em toda a sua extensão e que o poder público que deveria realizar ações que poderiam reduzir e coibir a sua degradação não executou nenhuma das diretrizes previstas no Plano Diretor, bem como os prazos estabelecidos não foram cumpridos.

Palavras-chave: Córrego Urbano. Degradação. Instrumento de Planejamento. Gestão Pública.

\section{ABSTRACT}

Interventions in Permanent Preservation Areas of urban creeks have, over the years, put them and their population at risk. In this scenario, we aimed to analyze the degradation of the Sangradouro creek in Cáceres, Mato Grosso; and to determine how the municipal management, through its Master Plan, has contributed to this process. We used a qualitative approach, involving bibliographical, field and documentary research, as well as interviews and a questionnaire. The results show that the watercourse is partly disfigured, and its degradation is visible throughout its extent; and that the public authority, who ought 
to have undertaken actions to reduce and curb the creek's degradation, did not execute any of the directives stated in the Master Plan, and the established deadlines were not met.

Keywords: Urban Creek. Degradation. Planning Instrument. Public Management.

\section{Introdução ${ }^{1}$}

O espaço, segundo Santos (1988, p. 64), é resultante de uma relação entre o homem e a natureza, onde ambos estão em constante transformação, ou seja, "a produção do espaço é resultado da ação dos homens agindo sobre o próprio espaço, através dos objetos naturais e artificiais".

Com o entendimento da produção do espaço por meio da ação do homem, Corrêa (2002) afirma que o espaço, do qual os geógrafos se ocupam, é um espaço social em estreita correlação com a prática social, cuja produção é resultante da ação empreendida pelo homem sobre a natureza, assim a sua organização reflete a forma como a população o utiliza.

Ao trazer essa compreensão de espaço para o espaço urbano, Corrêa (2000), assevera que esse é a expressão dos processos sociais e econômicos, portanto é resultado da organização das atividades humanas de maneira justaposta no meio geográfico e essas composições são responsáveis pela formação das cidades, das atividades contidas e a organização socioespacial.

Assim, é necessário, entender os fatores que influenciaram, em momentos distintos, as formas de apropriação do espaço. Desse modo, para a análise da cidade, conforme Carlos (2007, p. 11) é de fundamental importância que se realize "uma reflexão sobre a prática socioespacial que diz respeito ao modo pelo qual se realiza a vida na cidade, enquanto formas e momentos de apropriação do espaço".

Segundo Carmo e Vieira (2017, p. 779) "pensar no urbano é pensar no capital, ou seja, cidade enquanto lócus genuíno, por excelência, da produção e reprodução do capital". Ressalta-se que, conforme Carlos (1994), na sociedade capitalista, a produção do espaço urbano, ocorre de forma hierarquizada, dinamizada e segregada.

\footnotetext{
${ }^{1}$ Pesquisa realizada com apoio financeiro da Fundação de Amparo à Pesquisa do Estado de Mato Grosso (FAPEMAT)
} 
Dessa forma, Carmo (2017, p. 10) especifica que a lógica capitalista na produção do espaço, traz como resultado uma cidade segregada, onde se verifica localidades atendidas com todas as benesses urbanas e outras completamente abandonadas pelo poder público". Ressalta-se que essa é a realidade de muitas cidades, a maior parte da população vive na precariedade, enquanto outra, tem à sua disponibilidade toda infraestrutura e serviços urbanos, podendo exercer o seu direito de acesso à todos os espaços da cidade.

Entende-se; portanto, conforme Andrade e Carmo (2016), que a lógica capitalista na produção do espaço urbano dificulta o acesso da população de baixos rendimentos às localidades mais adequadas à habitação, consequentemente essa população é condicionada a ocupar as áreas periféricas, tanto no que se refere à localização distante do centro, como ao não atendimento pelos serviços urbanos, acrescenta-se ainda, aquelas em que não deveria ocorrer a ocupação por habitação, como, por exemplo, as Áreas de Preservação Permanente.

Destaca-se aqui nesse texto a ocupação de Áreas de Preservação Permanente de córregos urbanos. Quando ocorre a ocupação dessas áreas, segundo Vargas (2008), os canais fluviais são colocados em risco, gerando conflitos socioambientais, pois envolve questões relativas à sua preservação, o uso econômico da propriedade e o direito à moradia.

A ocupação das Áreas de Preservação Permanente ocorre, especialmente, em razão de uma expansão urbana desordenada, sem o devido planejamento que atenda aos interesses de todos os cidadãos, nesse contexto, as cidades têm apresentado os mais diversos problemas relacionados ao meio ambiente, à habitação, ao saneamento básico, dentre outros.

Em Cáceres pode-se evidenciar estes problemas no córrego Sangradouro, onde a expansão urbana foi se consolidando sem estudos prévios, alterando a paisagem do seu entorno, causando pressão sobre o canal, cuja intervenção que busque melhoras paisagísticas e sanitárias que possam elevar a qualidade de vida é uma necessidade para a população e um desafio para a gestão municipal.

Cáceres (figura 1) é um dos maiores municípios do estado de Mato Grosso, com uma área de $24.612 \mathrm{Km}^{2}$ (IBGE, 2016). Foi fundada em 06 de outubro de 1778, pelo governador Luís de Albuquerque de Melo Pereira e Cáceres, sendo denominado de Vila Maria do Paraguai, em homenagem à rainha D. Maria I de Portugal (RIBEIRO CHAVES e ARRUDA, 2011, p. 280). 
Cáceres no decorrer de sua história apresentou alteração em sua denominação, de acordo com Neves et. al. (2010, p. 8) o nome da vila foi alterado em 1979 para São Luiz do Paragaui e posterioremente, em "30 de maio de 1874 foi elevada à categoria de município, denominado São Luiz de Cáceres e que, mais tarde, em 1938, foi denominado simplesmente, Cáceres".

Conforme o site oficial da Prefeitura Municipal, Cáceres é considerado um polo regional, por oferecer serviços como: saúde, educação, lazer, exportação, quer na qualidade, quer na quantidade nos municípios que polariza. Segundo o Instituto Brasileiro de Geografia e Estatística (IBGE, 2016) a pecuária é uma das principais atividades econômicas do município, contendo um dos maiores rebanhos de gado bovino do Brasil e a atividade turística tem crescido nos últimos anos, destacando-se a pesca esportiva que atrai milhares de pessoas anualmente no Festival Internacional de Pesca.

O município pertence à bacia sedimentar do Pantanal, incluindo uma parte de dobramentos do Paraguai e apresenta três unidades geomorfológicas distintas: "a Província Serrana [...] a depressão do rio Paraguai [...] Pantanal”, maior planície inundável com mais de 140.000 km² de superfície (FERREIRA, 2005, p. 67).

Diante dessa importância do município de Cáceres na região sudoeste do Estado de Mato Grosso e por estar localizada em área pertencente ao complexo do Pantanal, e; por compreender que a preservação dos seus córregos urbanos é de fundamental importância para o equilíbrio do rio Paraguai e para a qualidade de vida da população, o objetivo desse texto foi o de apresentar o resultado da pesquisa que propôs a verificação de como o Plano Diretor de Cáceres, sendo um instrumento de gestão pública, contribui para regulamentar o uso do solo e coibir a degradação desses canais fluviais, bem como para o atendimento à toda a sociedade, tomando como objeto de estudo o córrego Sangradouro, tributário do rio Paraguai (Figura 1). 


\section{Materiais e métodos}

Para a realização da pesquisa recorreu-se à pesquisa bibliográfica, que foi de fundamental importância; pois por seu intermédio foi realizada a fundamentação teórica da análise. A pesquisa descritiva, outro procedimento metodológico utilizado, que concomitantemente com a pesquisa de campo proporcionou a descrição da situação de degradação do córrego Sangradouro em Cáceres na área urbana e o registro fotográfico. A observação em campo foi realizada em oito pontos (Figura 1), englobando não só o córrego Sangradouro, mas também um pequeno trecho de um de seus afuentes, o córrego Lava-pés.
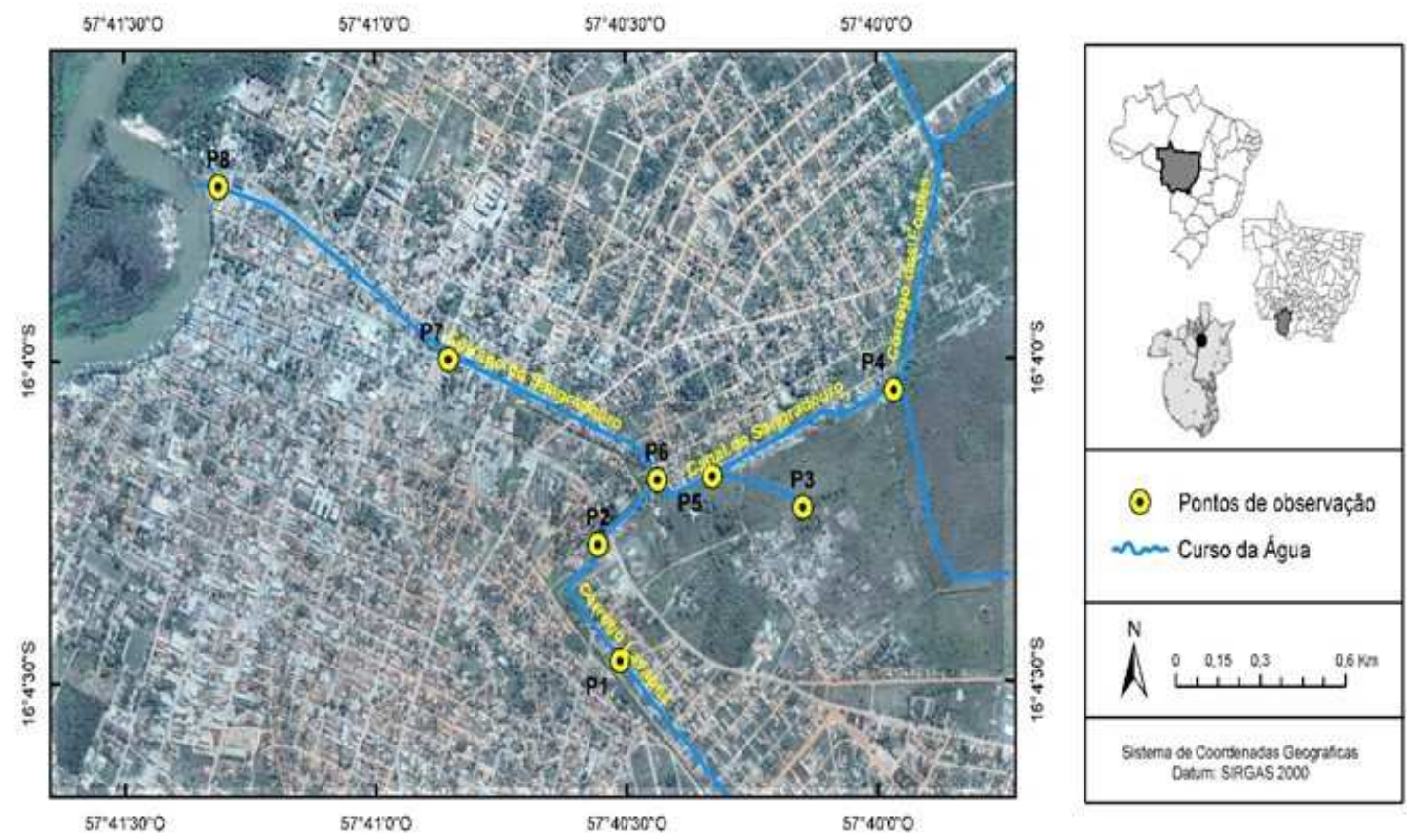

Figura 1 - Pontos observados no Córrego Sangradouro e Lava-pés no município de Cáceres, Mato Grosso em 2017. Organizada pelas autoras.

Para atingir os objetivos propostos foi utilizada também a pesquisa documental, por meio da qual analisou-se o Plano Diretor de Cáceres com o intuito de verificar se em sua elaboração houve a preocupação de estabelecer ações e diretrizes relacionadas à conservação e proteção das Áreas de Preservação Permanente. A análise desse documento em conjunto com a pesquisa de campo foi realizada para verificar sua eficácia para reduzir a degradação do córrego em foco. Ressalta-se que para a verificação da eficácia desse 
documento recorreu-se ainda à aplicação de questionário ${ }^{2}$ à representante da Secretaria Municipal de Indústria, Comércio, Meio Ambiente e Turismo (SICMATUR); da Secretaria de Planejamento e da empresa Águas do Pantanal e entrevista com moradores antigos.

\section{Resultados e discussão}

A Constituição Federal de 1988 (BRASIL, 1988), trata nos capítulos 182 e 183 da política urbana e a lei 10.257, de 10 de julho de 2001 (BRASIL, 2001), o Estatuto da Cidade, foi implementada para regulamentar esses capítulos. No art.1ำ do Estatuto encontra-se estabelecido que na execução da política urbana, será aplicado o previsto nesta lei.

O Estatuto da Cidade (BRASIL, 2001), no parágrafo único, especifica que para todos os efeitos; esta lei, estabelece normas de ordem pública e de interesse social que regulam o uso da propriedade urbana em prol do bem coletivo, da segurança e do bem-estar dos cidadãos, bem como do equilíbrio ambiental. Em seu artigo 40, assegura que o Plano Diretor serve como instrumento básico para o desenvolvimento e a expansão urbana.

Em conformidade com o artigo 40, o artigo 41 do Estatuto da Cidade (BRASIL, 2001) impõe a obrigatoriedade da implantação de Plano Diretor a todo município que apresente população acima de 20.000 habitantes, cidades metropolitanas ou aglomeradas, cidades turísticas, cidades que são alvos de implantação de grandes empreendimentos que podem causar impacto ambiental.

A constituição Federal de 1988 (BRASIL, 1998) apresenta um avanço para a questão urbana quando especifica que o planejamento das cidades deve ser realizado na esfera local, ao inserir em alguns incisos do artigo 30 o que compete aos municípios: o inciso I - atender os assuntos locais; o inciso II - suplementar a legislação federal e a estadual no que couber; inciso VIII - promover ordenamento territorial, mediante planejamento e controle do uso, parcelamento e a ocupação do solo urbano.

As leis examinadas, preveem a obrigatoriedade da realização do planejamento da cidade em nível local, sendo assim, procedeu-se a verificação de como o município de Cáceres atendeu

\footnotetext{
${ }^{2}$ As questões que compõem o questionário, bem como as respostas à elas encontram-se no quadro 1.
} 
essa exigência, como foi elaborado o seu Plano Diretor e se o que foi previsto nele foi executado e implementado de forma a contribuir para a minimização da degradação do córrego Sangradouro.

Cáceres foi fundada em 6 de outubro de 1778, o primeiro planejamento realizado foi em 1778, quando elaborou-se a planta básica de Vila Maria do Paraguai, e ficou estabelecido que as ruas que encontravam com o rio Paraguai, deveriam medir 60 palmos de largura (cada palmo equivalia a $22 \mathrm{~cm}$ ) e as travessas com medidas de 30 palmos, compondo os quarteirões de 360 palmos (Figura 2). O sistema de medida adotado na elaboração da planta só foi mudado em 1873 , pela câmara, quando houve a proposição de sistema de medida francês (informações obtidas em entrevista com o senhor Adilson Reis ${ }^{3}$ ).

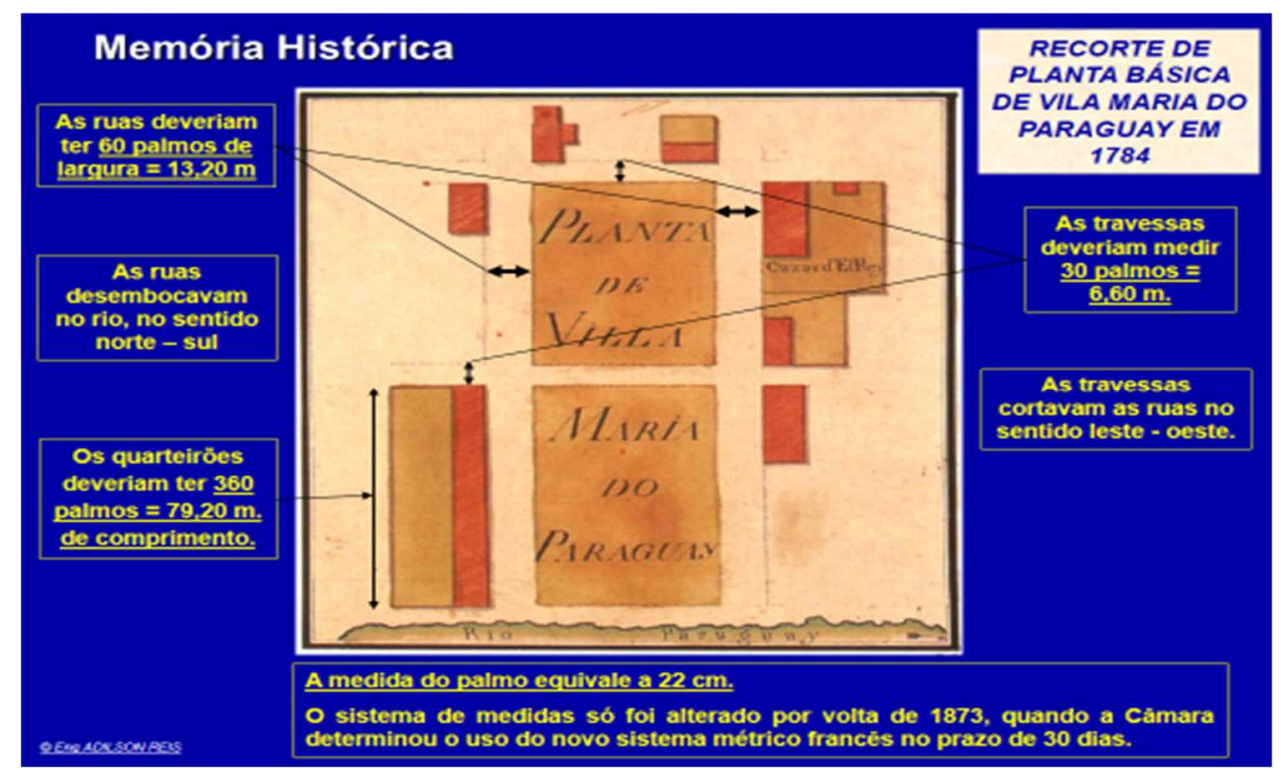

Figura 2 - Planta de Vila Maria do Paraguai em 1778. Fonte: Arquivo de Adilson Reis.

Entretanto, se passaram muitos anos sem um novo planejamento. Somente em 1995 que o município de Cáceres implantou o seu Plano Diretor. Depois de 15 anos, em 2010 a lei complementar no 90 de 29 de dezembro (CÁCERES, 2010), institui a atualização do Plano Diretor de Desenvolvimento do Município de Cáceres, seguindo o que estabelece o parágrafo 3ㅇ. do Estatuto da Cidade.

Foram realizadas audiências públicas para a elaboração do Plano Plurianual (PPA) para o período de 2010 a 2014, com o objetivo principal de realizar a "Sensibilização para a atualização do Plano Diretor" (CÁCERES, 2010), em atendimento ao inciso I do artigo 4ㅇ․ do Estatuto da Cidade (BRASIL, 2001) que dita a obrigatoriedade de promover audiências

\footnotetext{
${ }^{3}$ Morador antigo de Cáceres, engenheiro que prestou serviços à Prefeitura Municipal.
} 
públicas e debates com a participação da população e de associações representativas dos vários segmentos da comunidade. A participação da população, entretanto foi pequena.

Sobre a participação em audiências públicas França (2016) relata que ao realizar estudo sobre a revisão do Plano Diretor de Montes Claros em Minas Gerais, identificou que a participação social nas audiências foi restrita, a forma como elas foram organizadas não atingiram nem metade das regiões de planejamento, tão somente realizadas pelas exigências do artigo 45 do Estatuto da Cidade (BRASIL, 2001), de que "Incluirão obrigatória e significativa participação da população e de associações representativas dos vários segmentos da comunidade, de modo a garantir o controle direto de suas atividades e o pleno exercício da cidadania".

Pode-se inferir, assim, que as audiências se concretizam apenas para cumprirem a lei, mas sem a efetiva presença da população. É importante salientar que esta situação é recorrente também em outros municípios, como Cáceres, por exemplo.

Ao refletir sobre a pouca participação da sociedade nesses espaços de discussão da cidade e seu planejamento, França (2016) aponta que essa situação é reflexo de uma "descrença em relação aos processos políticos numa cidade dual e num momento em que sua participação deveria ser motivada, valorizada e reconhecida em função de seu conhecimento das realidades local e regional" (p. 129 - 130).

As audiências públicas possibilitam aos cidadãos exercerem o direito de apresentar propostas, assinalar soluções e alternativas; portanto é um espaço importante no exercício da cidadania (ANTONELLO, 2013, p. 245). Deste modo a população precisa se conscientizar sobre a necessidade de exercer esse direito e se tornar responsável pelo processo de elaboração do Plano Diretor municipal.

Para tanto, há necessidade de continuar sensibilizando a população da importância desse processo de planejamento e da sua participação, uma vez que não se pode esquecer que a partir do momento em que a população busca pensar os problemas e as soluções para a cidade, ela se constitui como parte do processo.

Sobre a participação da população, Antonello (2013, p. 248) argumenta que é "necessário colocar em prática mecanismos que fomentem a participação popular". Isto porque, em consonância com Maricato (2000, p. 180), "Partimos do pressuposto de que o plano urbano deve ser a expressão democrática da sociedade".

Destaca-se que deve haver o incentivo da participação da sociedade na elaboração e na revisão do Plano Diretor. Essa revisão está prevista no artigo 99, da lei complementar no 
90/2010 (CÁCERES, 2010), onde encontra-se explícito que no prazo máximo de cinco (05) anos após a promulgação desta lei, o Plano Diretor deverá ser avaliado quanto aos resultados da aplicação de suas diretrizes e instrumentos e das modificações ocorridas no espaço físico, social e econômico do município, procedendo-se às atualizações e adequações que se fizerem necessárias.

A previsão explícita no artigo 99, do Plano Diretor de Cáceres, está de acordo com o que está estabelecido no Estatudo da Cidade, de que o Plano Diretor deve ser revisto, pelo menos a cada 10 anos e que o Plano Plurianual, a lei de Diretrizes Orçamentárias e a Lei Orçamentária Anual, devem no momento de suas elaborações, atenderem de forma prioritária as diretrizes estabelecidas no Plano Diretor.

Entretanto, com atraso de três anos pelo estabelecido na lei complementar no 90/2010, mas dentro do prazo, conforme o parágrafo 3으, do artigo 40 do Estatuto da Cidade (BRASIL, 2001); em 2017, o Plano Diretor de Cáceres, encontrava-se em processo de revisão. Portanto, na presquisa realizada, analisou-se o Plano Diretor de 2010.

O Plano Diretor de Cáceres de 2010 apresenta como objetivo "instrumentalizar o processo de desenvolvimento, permitindo uma compreensão dos fatores Políticos Econômicos Financeiros e Territoriais, que mostram a situação e a necessidade do Município" (CÁCERES, 2010). Para atingir esse objetivo, todo Plano Diretor deve seguir os instrumentos urbanísticos presentes no Estatuto da Cidade, os quais possibilitam enfrentar o desafio de reduzir a desigualdade social, degradação ambiental e o desordenamento territorial.

Para reduzir o desordenamento territorial deveria ser posto em prática o artigo 89, do Plano Diretor de Cáceres, contido na Seção IV, que faz referência aos artigos 25 a 27 do Estatuto da Cidade, que trata do Direito de Preempção, o qual consiste na preferência do município na aquisição de imóveis que seja objeto de alienação onerosa entre particulares. Nesse artigo do Plano Diretor de Cáceres há a determinação de que o poder público municipal poderá exercer esse direito, sempre que o município necessitar de áreas para regularização fundiária, execução de projetos habitacionais, criando espaços públicos de lazer, implantando projetos de proteção das áreas verdes, históricos, paisagísticos, ordenando a expansão urbana (CÁCERES, 2010).

A vantagem do exercício do direito de preempção é que ele possibilita "a constituição de reserva fundiária e ordenamento e direcionamento da expansão urbana" (REBOUÇAS, 2007, p. 248). Este instrumento do Estatuto da Cidade também contribui, segundo o mesmo autor, para que o poder público possa adquirir progressivamente os imóveis que se fazem 
necessários ao melhor "planejamento da cidade, o que permite a constituição de uma reserva fundiária pelo município, facilitando a execução de seu Plano Diretor, principalmente, no que diz respeito à construção de habitação popular". (p. 250).

A execução desse direito é de grande importância para a cidade de Cáceres, pois em notícia de 2012, divulgada na página oficial da Prefeitura Municipal, sobre audiência pública realizada nesta mesma cidade, que teve como objetivo debater a etapa final do Plano Estadual de Habitação de Interesse Social (PNHIS), o Secretário de Estado das Cidades, Gonçalo Aparecido Barros, na ocasião apontou que o diagnóstico habitacional que utilizou dados do IBGE e do Cadastro Único de cada município, Cáceres, aparecia na terceira colocação em termos de necessidade habitacional, no ranking regional, sendo necessárias 15.238 Unidades habitacionais para sanar este déficit (ASCOM, 2012).

Ainda sobre a execução do direito de preempção, deve ser indicado no Plano Diretor quais são as áreas em que se aplicará esse instrumento. O Plano Diretor de Cáceres (CÁCERES, 2010), no parágrafo segundo, do artigo 89, expõe que uma lei municipal específica deverá ser elaborada, com esta finalidade. Entretanto, em contato com a prefeitura municipal obteve-se a informação de que esta lei ainda não foi elaborada e que no momento atual é que está em discussão a criação da mesma.

Observa-se que mesmo com este Plano Diretor de Cáceres, o município não utilizou os instrumentos jurídicos para o planejamento da cidade e ela continuou a se expandir de maneira desordenada, isto possibilitou a consolidação de problemas como a ocupação de áreas impróprias, cuja solução passa pelo estabelecimento de programas habitacionais que atendam a demanda dos munícipes.

Outro problema que poderia ser reduzido com o exercício do direito de preempção previsto no artigo 89 do Plano Diretor de Cáceres é o descaso com as áreas verdes. Verifica-se, no córrego Sangradouro que suas margens (Área de Preservação Permanente) estão ocupadas ou em processo de ocupação (Figura 3), se o artigo mencionado fosse efetivamente executado, poderia haver minimização da degradação desse canal fluvial. 


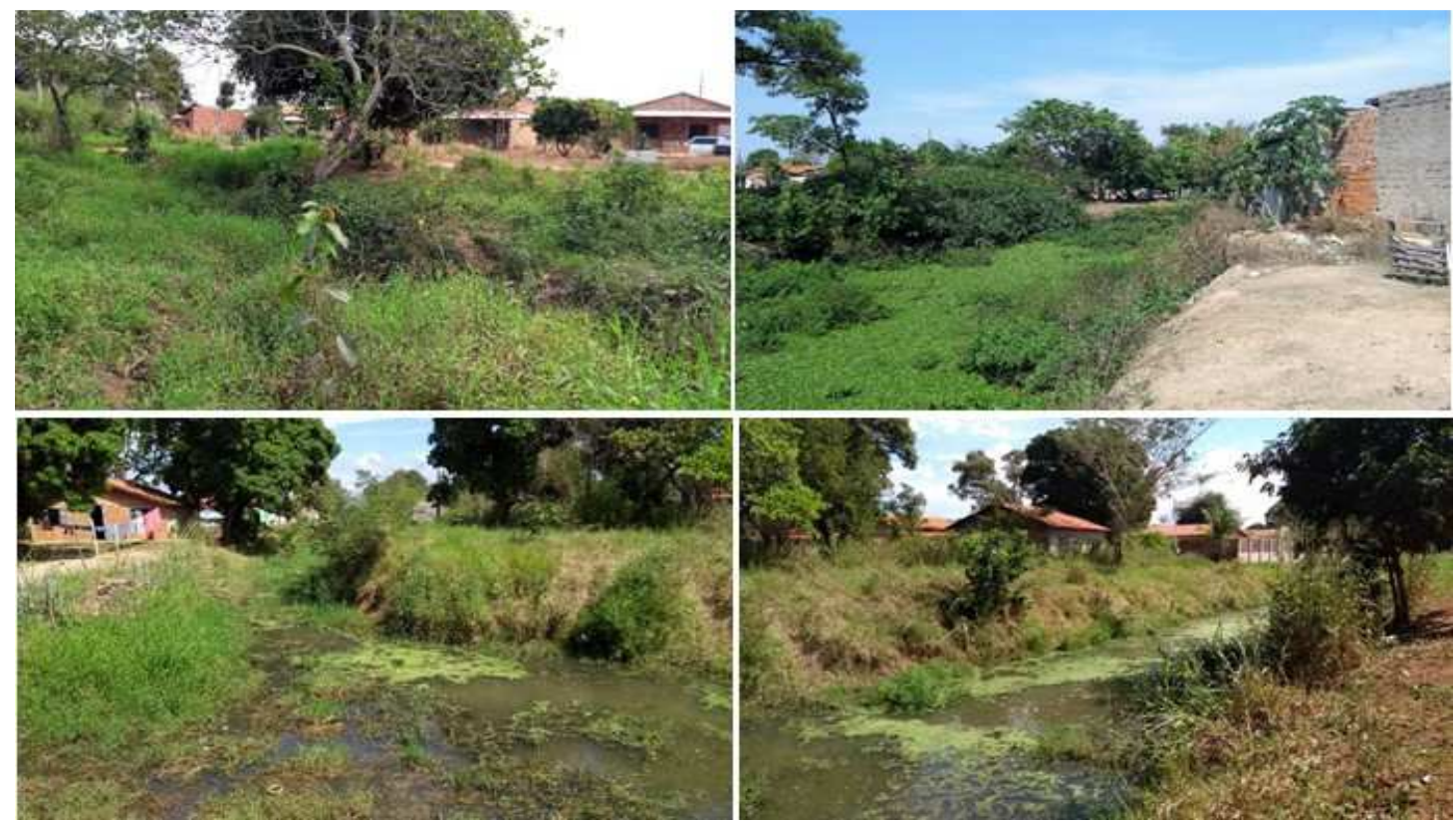

Figura 3 - Ocupação das margens do córrego. Fonte: Foto dos autores, janeiro de 2018.

A ocupação das margens do córrego está ligada à forma como foi produzido e reproduzido o espaço urbano, de maneira seletiva, atendendo o mercado de terras urbanas, que impossibilita o acesso da população à moradia; entretanto, ressalta-se que muitas vezes há ocupação também, especialmente com estruturas comerciais e industriais, que segue a lógica do capital, na qual a natureza representa o atraso.

A situação na qual se encontra o córrego, mostra a realidade inversa do ideal expresso no artigo 60, da lei no 90/2010 (CÁCERES, 2010), em que há a defesa da "sustentabilidade e o desenvolvimento local socialmente justo, ambientalmente equilibrado e economicamente viável, visando garantir qualidade de vida para as gerações presentes e futuras". Verifica-se neste artigo a valorização do desenvolvimento local que preze pela sustentabilidade, entretanto o que se percebeu foi que a realidade está longe do ideal apresentado no Plano Diretor.

Com o intuito de aprofundar mais nessa relação entre o real e o ideal, tomou-se para análise o cumprimento dos prazos estabelecidos no artigo 96 do Plano Diretor para a execução de ações que visem o cumprimento do que está previsto no artigo 92. Este artigo refere-se ao instrumento do Estatuto da Cidade "da transferência do direito de construir".

O Poder Público, conforme o exposto no artigo 92 do Plano Diretor, pode autorizar o proprietário de imóvel que esteja localizado em Zona de Adequação Ambiental a exercer em 
outro local ou alienar, de forma total ou parcial, o potencial construtivo quando se tratar de imóvel de interesse de preservação, exercendo função ambiental essencial, servindo a programas de regularização fundiária, habitação de interesse social; destinado à implantação de equipamentos urbanos e comunitários.

No quadro abaixo são apresentadas as ações previstas, os prazos e a situação de execução (se realizada ou não), conforme o estabelecido no artigo 96. Ressalta-se que a situação de execução da ação foi averiguada junto à Prefeitura Municipal por meio de questionário encaminhado à Secretaria Municipal de Indústria, Comércio, Meio Ambiente e Turismo (SICMATUR) e à Secretaria de Planejamento e à empresa Águas do Pantanal.

Observa-se como está exposto no quadro (1) que a análise do artigo 96 do Plano Diretor de Cáceres evidenciou o não cumprimento de todos os prazos nele estabelecidos. Apenas foi elaborado até o momento o código de obras e posturas municipais.

\begin{tabular}{|c|c|c|}
\hline Ações & Prazos & Situação \\
\hline $\begin{array}{l}\text { I - Elaboração do estudo para recuperação e determinação de } \\
\text { ações preventivas para as áreas de risco, incluindo levantamento } \\
\text { de loteamentos irregulares e conjuntos habitacionais de significado } \\
\text { social; }\end{array}$ & meses & Não realizada \\
\hline $\begin{array}{l}\text { Il - Elaboração do levantamento planialtimétrico das áreas urbanas } \\
\text { de todo o município; }\end{array}$ & $\begin{array}{c}12 \\
\text { meses }\end{array}$ & Não realizada \\
\hline III - Elaboração dos demais estudos conjunto de dados; & meses & Não realizada \\
\hline $\begin{array}{l}\text { IV - Revisão das leis de Perímetro Urbano, de Parcelamento do } \\
\text { Solo Urbano, dos códigos de Posturas Municipais, de Obras e } \\
\text { Tributário; e da divisão territorial dos bairros da sede municipal; }\end{array}$ & meses & $\begin{array}{l}\text { Apenas o código de } \\
\text { obras e posturas } \\
\text { municipais }\end{array}$ \\
\hline $\begin{array}{l}\text { V - Elaboração da lei de Uso e Ocupação do Solo Urbano e do } \\
\text { Código Ambiental, após o término do levantamento } \\
\text { planialtimétrico das áreas urbanas; }\end{array}$ & meses & Não realizada \\
\hline $\begin{array}{l}\text { VI - A elaboração do Zoneamento Municipal Ecológico e dos planos } \\
\text { setoriais serão compatibilizado com o zoneamento } \\
\text { socioeconômico ecológico do estado; }\end{array}$ & meses & Não realizada \\
\hline VII - A regulamentação dos instrumentos jurídicos e políticos; & $\begin{array}{c}12 \\
\text { meses }\end{array}$ & Não realizada \\
\hline
\end{tabular}

Quadro 1 - Cumprimento dos prazos para a execução das ações estabelecidas no Plano Diretor - 2010. *A partir da publicação da lei (29/12/2010). Fonte: lei complementar no 90/2010. Organizado pelas autoras. 
Dando prosseguimento na análise da relação entre o ideal e o real, procurou-se identificar as diretrizes relacionadas ao meio ambiente no Plano Diretor e buscar junto às Secretarias Municipais, se estas diretrizes foram executadas ou não. No quadro (2) abaixo podem ser visualizadas as respostas dadas por representantes delas.

\begin{tabular}{|c|c|}
\hline Ações e Justificativas & Execução \\
\hline 1. Ampliação de áreas verdes de uso público: Houve ampliação? & Não \\
\hline \multicolumn{2}{|l|}{$\begin{array}{l}\text { R: Não houve ampliação das áreas verdes, houve manutenção e revitalização de praças } \\
\text { urbanas (SIMACTUR, 2017). }\end{array}$} \\
\hline $\begin{array}{l}\text { 2. Ampliação de áreas de livre e fácil acesso público para lazer próximas à rio. Houve } \\
\text { ampliação ou criação? }\end{array}$ & Não \\
\hline \multicolumn{2}{|l|}{$\begin{array}{l}\text { R: Não. Porém existe um projeto em andamento para realizar a revitalização de mais de } 1 \\
\text { km da orla urbana de Cáceres (SIMACTUR, 2017). }\end{array}$} \\
\hline 3. Criação de unidades de conservação ambiental. Foram implantadas? & Não \\
\hline \multicolumn{2}{|l|}{ R: Não. Pois não houve projetos (SIMACTUR, 2017). } \\
\hline $\begin{array}{l}\text { 4. Promoção de programas de recuperação de praças e áreas de lazer. Foi desenvolvido } \\
\text { algum programa? }\end{array}$ & Sim \\
\hline \multicolumn{2}{|l|}{$\begin{array}{l}\text { R: Existem programas de recuperação de área degradada no município, assim como } \\
\text { manutenção e revitalização de todas as praças urbanas. O Plano de Recuperação de Áreas } \\
\text { Degradadas - PRAD que ocorreu recentemente foi da praça Barão. }\end{array}$} \\
\hline $\begin{array}{l}\text { 5. Proteção de áreas sujeitas à erosão e/ou inundações. Foi realizado algum projeto nesse } \\
\text { sentido? }\end{array}$ & Sim \\
\hline \multicolumn{2}{|l|}{ R: Somente no rio Paraguai, próximo a SIMACTUR. } \\
\hline $\begin{array}{l}\text { 6. Estímulo à geração de postos de trabalho nas ações de conservação ambiental. Foi criado } \\
\text { algum posto de trabalho nesta área? }\end{array}$ & Sim \\
\hline \multicolumn{2}{|l|}{$\begin{array}{l}\text { R:Teve um grande avanço na conservação ambiental com a criação da autarquia da "Águas } \\
\text { do Pantanal, responsável por todo o saneamento do município com a subsequente } \\
\text { fechamento do lixão e abertura do aterro sanitário (SIMACTUR, 2017). }\end{array}$} \\
\hline $\begin{array}{l}\text { 7. Fortalecimento e incentivo à programas de Educação Ambiental nas escolas. Houve } \\
\text { fortalecimento e incentivo à esse tipo de programa? }\end{array}$ & Sim \\
\hline \multicolumn{2}{|l|}{ R: Parceria Bicho do Pantanal atividades em cada unidade escolar. } \\
\hline $\begin{array}{l}\text { 8. Ampliação da fiscalização ambiental, estabelecendo sanções e penalidades aos } \\
\text { responsáveis por invasões em Áreas de Preservação Ambiental? }\end{array}$ & Não \\
\hline \multicolumn{2}{|l|}{ R: Não. Pois o município não descentralizou o Licenciamento Ambiental (SIMACTUR, 2017). } \\
\hline $\begin{array}{l}\text { 9. Construção de Estação de Tratamento de Esgoto, visando a despoluição dos córregos e } \\
\text { esgoto. Houve a construção da ETE? }\end{array}$ & Sim \\
\hline \multicolumn{2}{|l|}{$\begin{array}{l}\text { R: Porém não possuem uma estação de tratamento de esgoto que atende a cidade toda, } \\
\text { mas há estudos para que posteriormente seja feito. Existem algumas ETEs como: ETE } \\
\text { Guanabara, ETE Jardim aeroporto, ETE Cohab Nova e recentemente ETE Dom máximo, onde } \\
\text { são feitos total acompanhamento e qualidade do mesmo (Águas do Pantanal, 2017). } \\
\text { Programa Cáceres Recicla e Projeto Cáceres Ecológico (Secretaria Planejamento). } \\
\text { E há projetos para contemplar a implantação de rede coletadora de esgoto em todo o } \\
\text { município com uma ETE (SIMACTUR, 2017). }\end{array}$} \\
\hline $\begin{array}{l}\text { 10. Diagnosticar e melhorar as redes de abastecimento de água, de esgoto sanitário e de } \\
\text { drenagem urbana. Esta ação foi empreendida? }\end{array}$ & Sim \\
\hline \multicolumn{2}{|l|}{$\begin{array}{l}\text { R: Em questão de abastecimento de água a maior parte da cidade foi atendida referente a } \\
\text { melhoria na rede; Esgoto houve o aumento no tratamento de quase } 500 \text { casas (Águas do } \\
\text { Pantanal, 2017). } \\
\text { Foi diagnosticado toda a rede de abastecimento e os projetos se encontram avançados, } \\
\text { como a melhoria da ETAs e substituição de rede. Esgotamento sanitário foi diagnosticado e } \\
\text { o projeto se encontra em fase final, drenagem idem esgoto. }\end{array}$} \\
\hline $\begin{array}{l}\text { 11. As ocupações por moradias das Áreas de Preservação Ambiental têm sido atendidas } \\
\text { com fiscalização, nas margens dos córregos urbanos? }\end{array}$ & Não \\
\hline
\end{tabular}


R: Há alguns processos em andamento, mas não há fiscais para que atendem à demanda, por isso passam por ileso a ocupação dessas áreas (Secretaria de Obras (Fiscal), 2017.

12. Implantação, criação de estação de triagem e reciclagem do resíduo sólido, incentivo à $\operatorname{Sim}$ coleta seletiva. Que ações foram realizadas neste quesito?

R: As ações realizadas referente foram a utilização de caminhão baú para coleta, EPIs, container que foram postos em alguns pontos da cidade como praça da Feira, praça Barão, praça Duque de Caxias, houve por parte dos responsáveis uma conscientização referente a importância da coleta seletiva e algumas palestras em escola (Águas do Pantanal, 207). Com o fechamento do lixão foi criado uma cooperativa dos catadores do lixão, e então criou-se um local de triagem de resíduos. Desde então foram realizadas várias ações como a lei do Programa Cáceres Recicla e espalharam nas cidades containers para coletas de resíduos secos e úmidos e criaram as rotas para coletas.

Quadro 2 - Execução das ações previstas no Plano Diretor - 2010. Fonte: Questionário aplicada em outubro de 2016. Org. dos autores.

No item (5) do quadro (2), que trata da proteção de áreas sujeitas à erosão e/ou inundação, onde consta que foi realizado um projeto nesse sentido, verifica-se que esse projeto atendeu apenas o local onde se encontra a SIMACTUR, quanto as demais localidades na mesma situação (pontos, 1,2,3 e 4, da figura 1), nada ainda foi feito.

Em continuação a análise do quadro (2), nos itens (6, 9 e 10) a autarquia Águas do Pantanal consolidou a implantação de um aterro destinado ao depósito dos resíduos sólidos do espaço urbano, implementando ainda, locais públicos com ponto de coleta seletiva. Esta autarquia é responsável pela manutenção das Estações de Tratamento de Esgoto (ETEs) dos bairros: Guanabara, Jardim aeroporto, Cohab Nova, e a mais recente a do Dom Máximo, que atende a 500 residências. Foi realizada melhoria na rede de abastecimento de água e está com projetos de ampliação da rede de esgoto para atender a toda a cidade.

Com a implantação do aterro veio alguns requisitos como a coleta seletiva, onde foi implantada a cooperativa dos catadores, que atualmente encontra em situação difícil, pela falta de equipamentos e por falta de separação dos materiais por parte dos moradores que ainda não adquiriram o hábito de separar o resíduo orgânico do reciclável. Mais uma vez a análise demonstrou que muitas das diretrizes apontadas no Plano Diretor não foram executadas.

Sobre o ordenamento do território, fica claro em observação à expansão urbana e em contato com representantes do poder público municipal que a cidade em expansão não foi planejada e se expandiu de acordo com as necessidades e a oferta de espaços para este fim. Em consonância Silva (2015) relata que grandes problemas como a degradação dos córregos urbanos em Cáceres foram causados principalmente pela ocupação a partir dos anos de 
1970, quando houve a urbanização das proximidades das margens dos córregos de forma desordenada, em paralelo à ausência de políticas que visassem a elaboração e execução do planejamento.

A pesquisa empreendida também se atentou à verificação da transformação da paisagem, especificamente à margens e ao entorno do córrego Sangradouro, que é o objeto principal dessa pesquisa, foi verificado em campo e em fotografias antigas a transformação da sua paisagem (Figura 4) e a sua degradação. Comparando as fotografias, fica evidenciada essa tranformação da paisagem. A primeira fotografia é do ano de 1958, a segunda de 1970, a terceira de 1978 e a última de 2018.
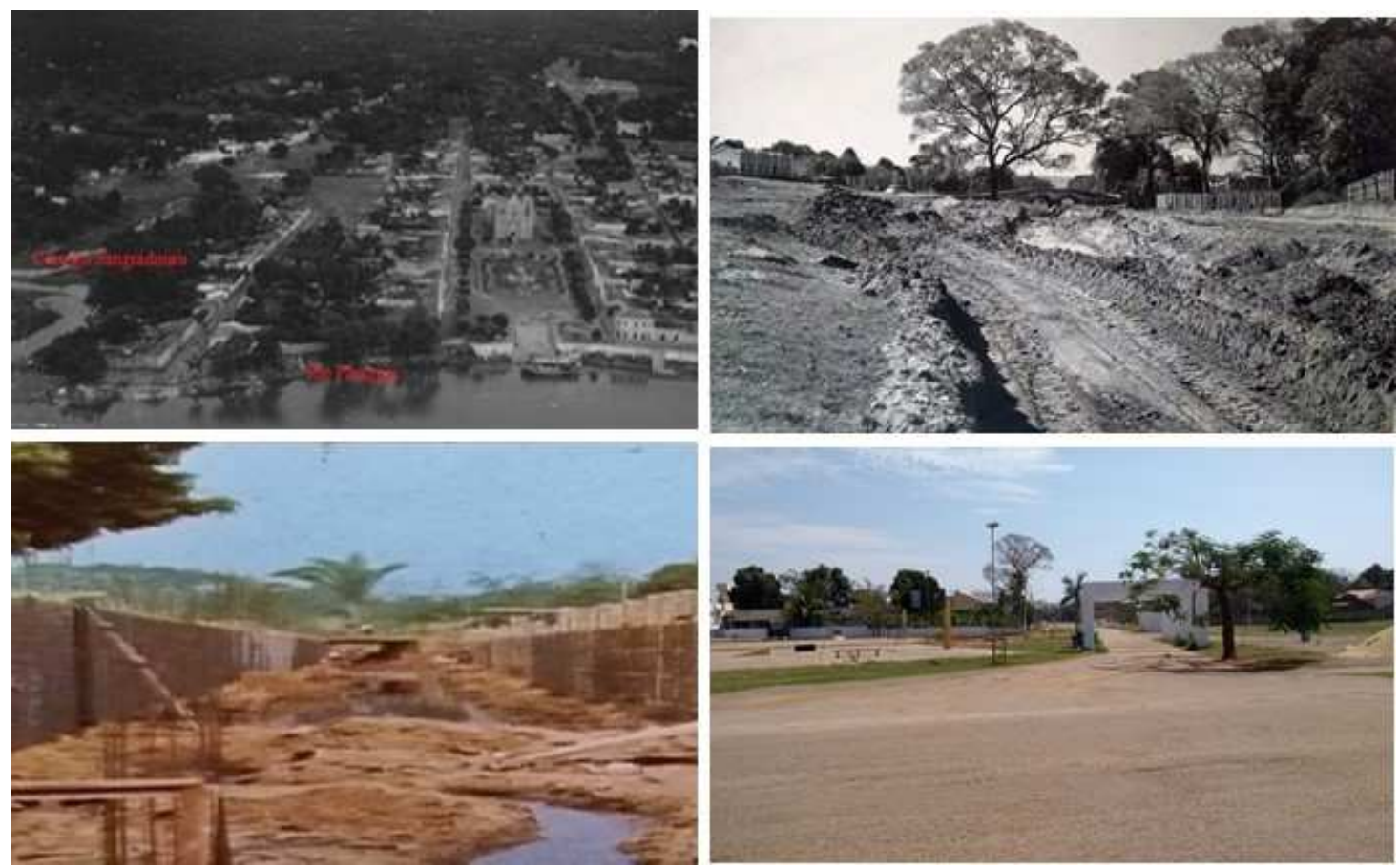

Figura 4 - Retilinização e Canalização e cobertura do córrego Sangradouro em trecho de 2km. Fontes: IBGE, Museu Histórico Municipal e Senhores Figueiredo Souza e Evangelista Souza.

Observa-se que essas interferências no córrego, promoveram; neste trecho retilinizado, canalizado e coberto; a total descaracterização de sua paisagem, sendo transformada completamente em artificial, hoje ocupada como local de lazer e realização de eventos.

Sobre esse processo implementado no córrego, os moradores antigos entrevistados afirmaram que antes de começarem a canalização, esse canal fluvial já era utilizado para despejo de esgoto doméstico; entretanto, após a intervenção o descarte de esgoto continuou a ser verificado no córrego. 
locca (2000, p. 3) especifica que "a influência antrópica sobre esse curso de água ocorre, com maior intensidade, sendo utilizado como receptor de esgoto bruto". Este canal agora, em parte, fechado, retém todo tipo de esgoto e deságua no rio Paraguai sem nenhum tratamento. Este processo fez com que as águas que corriam, se encontrem hoje encobertas, longe dos olhos da população e do visitante.

A alteração foi realizada em prol da urbanização do entorno do córrego, pois é intensa e este processo ainda está em curso, sendo identificadas muitas casas ainda em fase de construção, especialmente nos trechos à montante. Esta urbanização é deficitária, pois muitos dos bairros do entorno são carentes de infraestrutura como asfalto e rede de esgoto.

As casas em sua maioria são de baixo padrão, abrigando uma população de baixo poder aquisitivo. Entretanto, nos pontos mais próximos da área central, verifica-se a existência de edificações mais estruturadas condizentes com uma população de rendimentos mais elevados e a infraestrutura urbana se apresenta de melhor qualidade, pelo menos no que se refere ao asfalto.

Em todo o percurso do córrego se verifica resíduos sólidos em suas margens, a presença de canos para despejo de esgoto doméstico diretamente no canal (Figura 5). Em alguns pontos, especialmente na área de confluência dos canais de drenagem artificial com o córrego, a presença do esgoto é mais sentida, por conta do odor que se exala no ar. Ressalta-se que esses dejetos recebidos pelo córrego chegam até o rio Paraguai através da sua confluência.

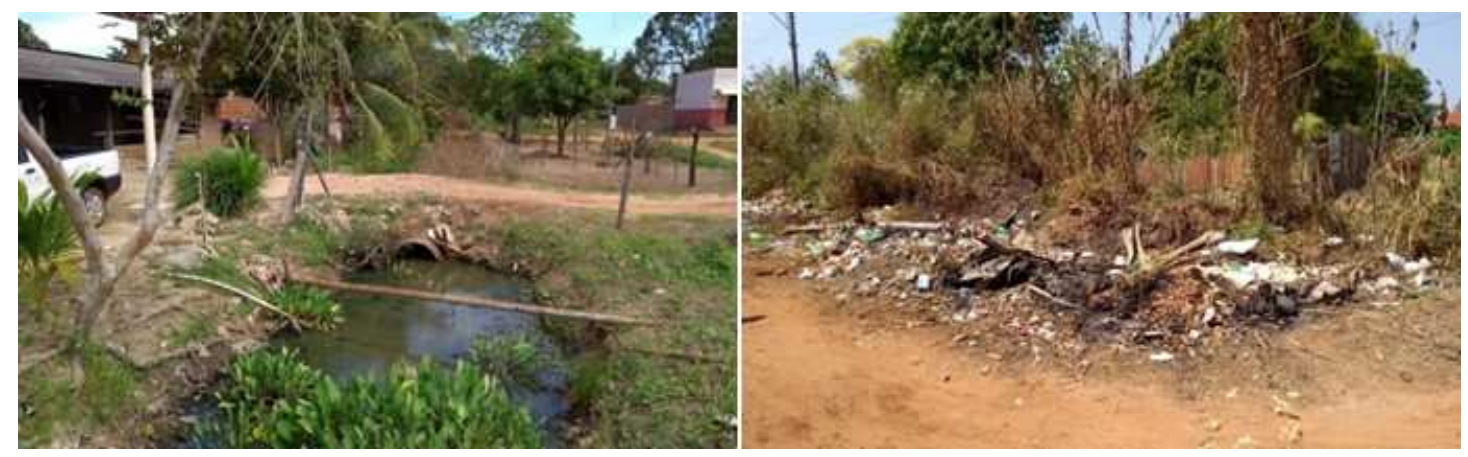

Figura 5 - Resíduos sólidos e canos de esgoto no córrego Sangradouro. Foto dos autores, janeiro de 2018.

A área de percurso do córrego em área urbana apresenta em alguns pontos, alto risco de inundação, este risco foi potencializado com a sua retilinização e canalização, como 
apontam Aguiar e Rosestolato Filho (2012), uma vez que promoveram o seu afunilamento e reduziu a sua eficiência na drenagem.

O descaso com a preservação do córrego pela gestão pública pode ser percebido quando se verifica a abertura de ruas bem às suas margens (Figura 6), promovendo a retirada da vegetação originária que proporciona o equilíbrio ao ambiente fluvial. Como pode ser observado a expansão urbana promoveu grandes mudanças à paisagem do entorno do córrego Sangradouro e estas mudanças se mostram negativas no que concerne a preservação desse canal.
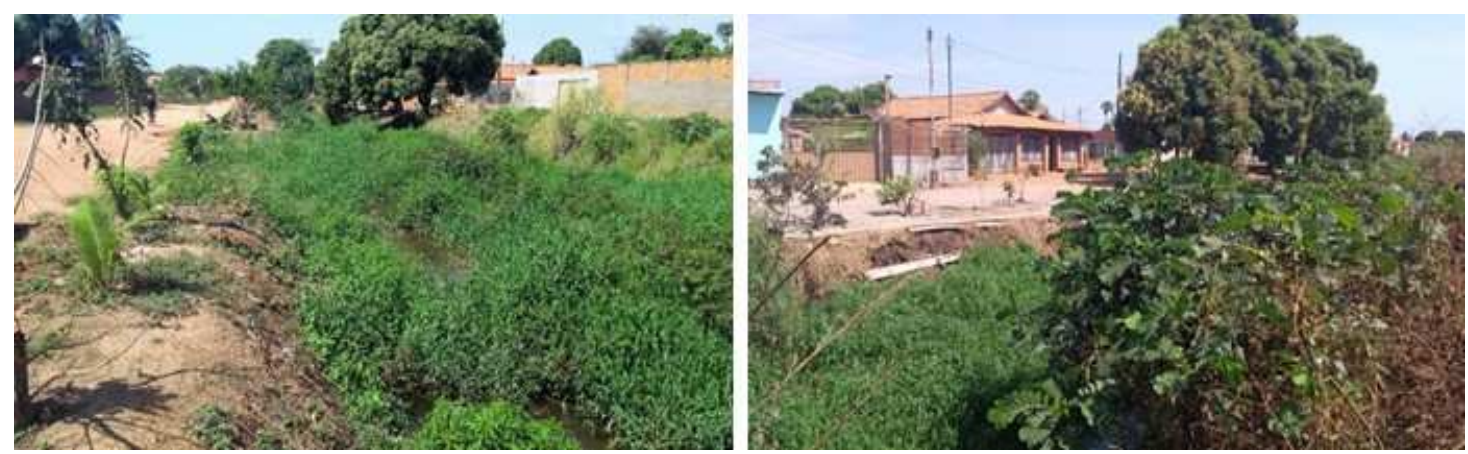

Figura 6 - abertura de ruas às margens do córrego Sangradouro. Foto dos autores, janeiro de 2018.

Quanto à preservação das áreas verdes, Milaré (2004, apud DAMIS e ANDRADE, 2006, p. 26) explicitam que ela tem como objetivo "ordenar a ocupação espacial, visando contribuir para o equilíbrio do meio ambiente."

Destaca-se que a falta de planejamento, que tenha preocupação com o meio ambiente e a população de baixa renda, trouxe problemas para a cidade, pois há ocupação de áreas impróprias e para se resolver esta situação são necessários programas habitacionais que atendam a demanda da população que se encontra em áreas de riscos ou de preservação, ou seja, "para a cidade ilegal não há planos, nem ordem. Aliás ela não é conhecida em suas dimensões e características. Trata-se de um lugar fora das idéias." (MARICATO, 2000, p. 122).

Contudo, verifica-se na cidade, um "discurso pleno de boas intenções, mas distante da prática" (MARICATO, 2000, p. 124), isto é que o se pôde demonstrar analisando o Plano Diretor (o ideal) e a situação de degradação e transformação do córrego Sangradouro (o real). É mais frequente parte do Plano ser cumprida ou então ele ser aplicado apenas em 
determinados setores da cidade. Sua aplicação segue a lógica da cidadania restrita a alguns (MARICATO, 2000).

Cada município passa por variados problemas que são gerados pelo setor econômico capitalista, que visa sempre o crescimento do capital, sem ao menos pensar nas consequências, afetando o ambiente natural, portanto a lógica capitalista na produção do espaço urbano como evidenciada por Botelho (2007), Carlos (2007), Corrêa (1989), Santos (1988) se verifica em Cáceres.

Desta forma entende-se que todos os municípios necessitam de Plano Diretor, elaborado com a participação efetiva da população, que considere a realidade local, não somente transpondo ações a serem realizadas em outros municípios, para que o planejamento e a gestão da cidade sejam orientados por este documento, proporcionando crescimento com sustentabilidade e oportunizando aos munícipes uma vida de qualidade e bem-estar.

Entende-se que o Plano Diretor sendo elaborado de forma a considerar a realidade local e a gestão pública, por meio de suas secretarias e diversos departamentos, ao seguir as diretrizes nele previstas, fazendo diagnóstico da situação social, econômica e ambiental, elaborando projetos com base em estudos sérios, tomando as providências cabíveis, a sustentabilidade na cidade pode ser algo a ser alcançado.

Entretanto, como já foi escrito antes, há a necessidade de que a sociedade comece a participar, opinar e defender ações que visem o bem-estar de todos os seus setores, bem como exija a implementação das ações e o cumprimento dos prazos pré-determinados. Em consonância com Sánches (1999, p. 130), entende-se a necessidade de "que ampliem as exigências da sociedade e garantam sua presença ativa na condução dos destinos das cidades", lembrando dos argumentos de França (2016, p. 119) que afirma que o Plano Diretor deve elevar todas as mudanças em curto e médio prazo, de modo preventivo.

Entretanto, com a revisão do Plano Diretor de Cáceres, iniciada em 2017, espera-se que nesse processo sejam levados em conta, efetivamente, todos os requisitos exigidos pelo Estatuto da Cidade. De início se percebe o intuito de fazer o planejamento dentro das normas e com a colaboração de todos os departamentos, sendo um grande passo o convênio realizado entre a Prefeitura e a Universidade do Estado de Mato Grosso. O Convênio conta com os seguintes termos: 
O termo de cooperação e convênio no 004/2017/PGM, convênio que entre si celebram a Prefeitura Municipal de Cáceres - MT e a Universidade do Estado de Mato Grosso - UNEMAT, tendo como interveniente/anuente a Fundação de Apoio ao Ensino Superior Público Estadual - FAESPE, considerando os interesses recíprocos e o regime de mútua cooperação entre as partes; considerando o artigo 24, inciso XIII, combinado com os artigos 116 e 117 da lei 8.666/93. Para execução de estudos, pesquisas e serviços referente a: Plano Diretor Municipal; Plano de Mobilidade Urbana; Cadastro territorial Multifinalitário; Reestruturação Fiscal e Tributária com vista ao apoio da gestão municipal e regularização fundiária, por um período de 18 (dezoito) meses a contar da assinatura deste instrumento, em conformidade com o Plano de Trabalho e Anexos aprovado pelos partícipes e que integra o presente instrumento. (CÁCERES, 2017).

É mister, neste processo de revisão a busca por alternativas para reduzir os problemas urbanos, de modo a promover a justiça social e democratizar o acesso à cidade ambientalmente equilibrada. Não se pode esquecer, conforme França $(2016$, p. 128) que "o Plano Diretor é o arranjo de diretrizes urbanas e não um 'cardápio de obras'."

É importante destacar que não bastam somente as técnicas e pesquisas, há a necessidade de políticas públicas voltadas ao incentivo na busca da sustentabilidade por parte da gestão pública, apoiando as iniciativas que visam o cuidado com os bens públicos, como por exemplo, às associações de reciclagem, à sensibilização quanto a importância da conservação dos recursos naturais para a manutenção de um ambiente equilibrado e a qualidade de vida na cidade. Para tanto é de suma importância que o município tenha um 'Plano Diretor Participativo' muito bem elaborado para realizar as ações cabíveis e necessárias para alcançar esse objetivo.

Os Planos Diretores são instrumentos essenciais para promover os usos adequados e sustentáveis dos recursos naturais, bem como a equidade social. Entretanto o que se verifica é que na grande maioria dos municípios, assim como em Cáceres, os Planos Diretores são elaborados apenas para cumprir uma exigência do Estatuto da Cidade, sem os quais não consegue acesso aos investimentos por parte do governo federal, sendo escritos por uma equipe que desconhece a realidade local. Portanto os Planos Diretores não abarcam as reais necessidades da cidade, nem tão pouco todos os cidadãos, não se vê na prática a implantação e efetivação das ações previstas, estando o espaço urbano, o real, muito distante do ideal. 


\section{Considerações finais}

$\mathrm{Na}$ atualidade, onde se observa que a produção do espaço e a transformação da paisagem são desencadeadas, especialmente para atender ao capital, há uma promoção e intensificação da degradação ambiental.

Ficou evidenciada pela pesquisa realizada a situação de degradação em que se encontra o córrego Sangradouro. A urbanização do entorno é intensa e este processo ainda se manifesta na atualidade, muitas novas edificações estão sendo levadas a cabo, especialmente a montante do canal. Esta urbanização verificada é deficitária, podendo assim ser afirmada em razão da carência de infraestrutura.

A população residente às proximidades e até mesmo na Área de Preservação Permanente é de baixo poder aquisitivo, entretanto, nas áreas mais próximas do centro, a presença de uma população com rendimentos mais elevados, pode ser verificada, isto fica evidenciado nas casas de melhor padrão e na infraestrutura urbana que se apresenta de melhor qualidade, pelo menos no que se refere à pavimentação asfáltica.

Em todo o percurso do córrego Sangradouro é possível visualizar em suas margens resíduos sólidos e rejeitos, também alguns canos utilizados para o despejo de esgoto doméstico no canal. Entende-se que a gestão municipal é responsável por realizar a fiscalização das ações nas Áreas de Preservação, mas o que se verifica é o próprio poder público promovendo atitudes que contribuem com a degradação do córrego como a abertura de ruas às suas margens.

As alterações realizadas no córrego Sangradouro como a sua retilinização, canalização e pavimentação seguem a lógica de várias cidades brasileiras, onde o descaso promove a sua degradação ao ponto de os moradores exigirem a sua encoberta para melhorar a imagem da cidade.

Nesse contexto, defende-se a necessidade de implantação de Estação de Tratamento de Esgoto - ETE que atenda todos os bairros da cidade, para reduzir a contaminação dos córregos urbanos, bem como do próprio rio Paraguai; e, melhorar a saúde das pessoas que residem em Cáceres; a realização de coletas de resíduos regularmente; campanhas de 
conscientização para não descartar resíduos em ambientes inapropriados; a elaboração de projetos de revitalização das margens dos córregos urbanos.

Somadas à estas ações, se constitui de extrema relevância a implementação de políticas públicas voltadas a buscar meios de preservação e conservação dos córregos urbanos para assegurar a sustentabilidade do presente e do futuro desses canais, lembrando que os córregos urbanos afetados em Cáceres deságuam no rio Paraguai, este representa suma importância para a manutenção do complexo do pantanal.

Ao analisar o Plano Diretor de Cáceres identificou-se que as ações previstas que poderiam direta ou indiretamente contribuir com a redução da degradação do córrego Sangradouro, como os demais, não foram executadas, desta forma este instrumento, na cidade, se constitui apenas em um elemento figurativo, que não é posto em prática, pelo menos parece que não houve disposição suficiente para isto.

Sendo assim, defende-se que um dos instrumentos importantes para solucionar os problemas urbanos é o Plano Diretor, essencial para promover o uso adequado e sustentável dos recursos naturais, bem como o controle da qualidade social. Contudo, verifica-se que a grande maioria dos municípios elabora o Plano Diretor em consonância com o Estatuto da Cidade; porém não abarca as reais necessidades da cidade, nem tão pouco todos os cidadãos. Não se vê na prática a implantação e efetivação das ações previstas; como resultado, observa-se o espaço urbano, o real, muito distante do ideal.

Ressalta-se que todo Plano Diretor deve seguir os instrumentos urbanísticos presentes no Estatuto da Cidade, os quais possibilitam enfrentar o desafio de reduzir a desigualdade social e a degradação ambiental, porém na sua elaboração e sua revisão, deve-se atentar para a realidade a que se está planejando e que as diretrizes apontadas sejam realmente efetivadas.

Muitas vezes a não aplicabilidade do Plano Diretor é resultado da forma como ele foi elaborado. Entende-se que o Plano Diretor sendo elaborado de forma a considerar a realidade local, com a participação efetiva da sociedade civil, a tendência é a produção de uma cidade mais justa, igualitária e ambientalmente equilibrada.

Por fim, conclui-se que a pesquisa realizada ao promover uma reflexão sobre as ações previstas no Plano Diretor e não executadas e ao ressaltar que esse documento é essencial 
para as cidades que desejam um planejamento sério, chama a atenção do poder público municipal para o desempenho de suas funções de forma isonômica, pois só assim se alcança o bem-estar socioambiental, devendo todos reunir em prol de uma solução para as questões ambientais dos córregos urbanos, que não só afetam a natureza como também à toda a população. Além disso, entende-se que o caso estudado pode servir de exemplo para cidades de outros países.

\section{Referências bibliográficas}

AGUIAR, D. P.; ROSESTOLATO FILHO, A. Os impactos da urbanização na dinâmica dos canais fluviais de Cáceres - MT. RCA Revista Cientifica da Ajes, 2012, v. 3, n. 7. Disponível em: <http://www.revista.ajes.edu.br/index.php/RCA/article/view/136/54>. Acesso em 08 jun. 2017.

ANDRADE, J. A.; CARMO, J. A. A Expansão Urbana Desordenada e suas Consequências para os Córregos Urbanos e a Transformação da Paisagem. In: 8a JORNADA CIENTÍFICA DA UNEMAT. Anais eletrônicos. CáceresMT, 2017. V. 8, p. 1-5. Disponível em: < http://siec.unemat.br/anais/!default/impressaopdf.php?r=OTMzOA==\&i=NTUONjM=\&p=LOFycXVpdm9zL2NvcnJpZ2Ikb3MvMTQyMTktNTUONjMucGRm\&y=M $A==\& v=M A==\& d=S Q==\&$ cache=1527016352>. Acesso em 20 fev. 2018.

ANTONELLO, I. T. Potencialidade do planejamento participativo no Brasil. Sociedade \& Natureza, Uberlândia, 2013, v. $\quad 25, \quad$ n. $\quad 2, \quad$ p. $\quad 239 \quad-254 . \quad 25$ Disponível $\quad$ em: <http://www.seer.ufu.br/index.php/sociedadenatureza/article/viewFile/19752/pdf>. Acesso em 30 mai.2017.

ASCOM - Assessoria de Comunicação da Prefeitura Municipal de Cáceres. Região sudoeste é terceira do Estado em déficit habitacional. 2012. Disponível em: <\&lt;http://www.caceres.mt.gov.br/Noticia/1576/regiaosudoeste-e-terceira-do-estado-em-deficit-habitacional\#.WuMfm4jwbIV\&gt>. Acesso em 13 abril 2016.

BOTELHO, A. O urbano em fragmentos: A produção do espaço e da moradia pelas práticas do setor imobiliário. São Paulo: Annablume, 2007. ISBN 978-85-7419-745-6.

BRASIL. Constituição da República Federativa do Brasil. 1988. Senado Federal. Disponível em: <https://www2.senado.leg.br/bdsf/bitstream/handle/id/518231/CF88_Livro_EC91_2016.pdf>. Acesso em 15 ago.2016. ISBN: 978-85-7018-698-0

BRASIL. Lei no 10.257, de 10 de julho de 2001. Estatuto da cidade. Regulamenta os art.182 e 183 da Constituição Federal e dá outras providências. Disponível em: <http://www.planalto.gov.br/ccivil_03/leis/leis_2001/l10257.htm>. Acesso em 15 ago.2018.

CÁCERES. Lei Complementar no. 90, de 29 de dezembro de 2010. Institui a atualização do Plano Diretor de Desenvolvimento do Município de Cáceres. Plano Diretor de Desenvolvimento de Cáceres - MT, Cáceres, 2010.

CÁCERES. Prefeitura Municipal de Cáceres. Termo de cooperação e convênio no 004/2017/PGM. 2017.

CARLOS, Ana Fani Alessandri. Repensando a Geografia Urbana: uma nova perspectiva se abre, In: CARLOS, Ana Fani Alessandri (Org.). Os caminhos da reflexão sobre a cidade e o urbano. São Paulo: EDUSP, 1994, p. 157-198. ISBN: 85-314-0182-8.

CARLOS, A. F. A. O Espaço Urbano: novos escritos sobre a cidade. São Paulo: FFLCH, 2007. Disponível em: <http://gesp.fflch.usp.br/sites/gesp.fflch.usp.br/files/Espaco_urbano.pdf>. Acesso em 05 abr. 2016. ISBN: 97885-7506-144-2.

CARMO, J. A. A lógica capitalista na produção do espaço urbano e as situações de vulnerabilidade social na cidade. In: ENANPEGE. GEOGRAFIA, CIÊNCIA E POLÍTICA: do pensamento à ação, da ação ao pensamento. 


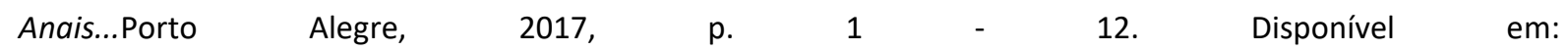
<http://www.enanpege.ggf.br/2017/anais/arquivos/GT\%2001/1143.pdf>. Acesso em 20 fev.2018.

CARMO, J. A.; VIEIRA, W. B. Aspectos socioeconômicos e habitacionais da população residente na Área de Preservação Permanente no córrego Jaracatiá em Colíder, MT. Geografia, Londrina, 2017, v. 26. n. 1. p. 779 793.

CORRÊA, R. L. Espaço: um conceito-chave da Geografia. In: CASTRO, I. E.; GOMES, P. C. C.; CORRÊA, R. L. (Orgs.). Geografia: conceitos e temas. 2a edição - Rio de Janeiro, BERTRAND BRASIL, 2000, p. 15 - 47. ISBN: 85-2860545-0.

CORRÊA, R. L. O espaço urbano. São Paulo: Ática, 1989. ISBN 85-08-03260-9.

DAMIS, R. C. B.; ANDRADE, T. S. A inaplicabilidade do código florestal em área urbana. Evocati Revista, $2006, \mathrm{n}$. 12, p. 01 - 21.Disponível em: <http://www.egov.ufsc.br/portal/sites/default/files/anexos/31188-34535-1PB.pdf>. Acesso em 15 mar. 2017.

FERREIRA, E. Planejamento de transporte cicloviário: o caso de Cáceres - MT. 2005, 169 f. Dissertação (Mestrado em Geografia) - Universidade Federal do Rio de Janeiro, COPPE, Rio de Janeiro, 2005.

FRANÇA, I. Planejamento urbano e participação social em cidade média: a revisão do Plano Diretor de Montes Claros - MG. GeoTextos, 2016, v. 12, n. 2. p. 107 - 134,. Disponível em: <https://portalseer.ufba.br/index.php/geotextos/article/view/18117>. Acesso em 12 abr.2017.

INSTITUTO BRASILEIRO DE GEOGRAFIA E ESTATÍ́sTICA - IBGE. Diretoria de Pesquisas - DPE - Coordenação de População $e$ Indicadores Socias - $\quad$ COPIS. 2016. Disponível em: <https://cidades.ibge.gov.br/brasil/mt/caceres/historico>. Acesso em 05 ago. 2016.

IOCCA, F. A. S. Caracterização limnológica do córrego Sangradouro nas épocas de seca e de chuva Cáceres/MT. 2000. 83 f. Dissertação (Mestrado em Ecologia) - Instituto de Ciências Biológicas, Universidade de Brasília, Brasília, 2000.

MARICATO, E. As idéias fora do lugar e o lugar fora das idéias: Planejamento urbano no Brasil. In: ARANTES, O. B. F.; VAINER, C.; MARICATO, E. A cidade do pensamento único: desmanchando consensos. Petrópolis: Vozes, 2000, p. 121 - 192. ISBN: 85-326-2384-0.

NEVES; R. J.; NEVES, S. M. A. S.; CASARIN, R. Sistema de informação turística geográfica de Cáceres/MT - Brasil: subsídios ao planejamento e desenvolvimento local. In: VI SEMINÁRIO LATINO-AMERICANO DE GEOGRAFIA FÍSICA. II SEMINÁRIO IBERO-AMERICANO DE GEOGRAFIA FÍSICA. Anais...Universidade de Coimbra, 2010, p. 1 17. Disponível em: <http://www.uc.pt/fluc/cegot/VISLAGF/actas/tema5/ronaldo>. Acesso em 03 ago. 2016.

REBOUÇAS, K. B. A. T. A eficácia do Direito de Preempção no Plano Diretor. Revista Direito e Liberdade, Mossoró, 2007, v. 6, n. 2, p. 233 - 252.

RIBEIRO CHAVES, O.; ARRUDA, E. F. História e memória Cáceres. Editora UNEMAT, 2011. ISBN: 978-85-7911061-0.

SANTOS, M. Metamorfoses do espaço habitado. São Paulo: Hucitec, 1988. ISBN: 85-271-0068-1.

SÁNCHEZ, F. Políticas urbanas em renovação: uma leitura crítica dos modelos emergentes. Revista Brasileira de Estudos Urbanos e Regionais. 1999, n. 1, p. 115 - 132.

SILVA, J. L. Expansão urbana e suas implicações, morfológica e sedimentológica na bacia hidrográfica do córrego Olhos D'Água em Cáceres - Mato Grosso. 2015. 63 f. Trabalho de Conclusão de Curso (Graduação em Geografia) - Universidade do Estado de mato Grosso - UNEMAT, Cáceres - MT, 2015.

VARGAS. H. L.; Ocupação irregular de APP urbana: um estudo da percepção social acerca do conflito de interesses que se estabelece na lagoa do Prato Raso, em Feira de Santana, Bahia. SITIENTIBUS. Feira de Santana, 2008, $\quad$ n. $39, \quad$ p. $\quad 7 \quad$ - $\quad 36 . \quad$ Disponível $\quad$ em: <http://www2.uefs.br/sitientibus/pdf/39/1.1_ocupacao_irregular_de_app_urbana.pdf>. Acesso em 04 nov. 2016. 